


\section{Göschens Lehrbücherei}

1. Oruppe

Reine und angewandte Mathematik

Band 22

Affine Differentialgeometrie

Von

Professor Dr. Erich Salkowski

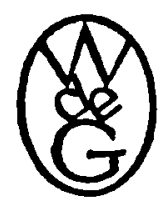

Walter de Gruyter \& Co.

vormals G.J. Goschen's che Verlagshandiung

J. Guttentag, Verlagsbucbhendlung-Georg

Berlin W Io und Leipzig 


\section{Affine}

\section{Differentialgeometrie}

Von

\section{Dr. Erich Salkowski}

o. Professor an der Teehnisehen Hochschule Berlin

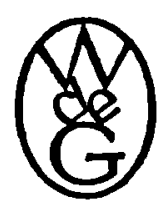

Walter de Gruyter \& Co.

rormalsG. J. Goschen'sche Verlagshandlong

J. Guttentag, Verlagsbuchbandluag-Georg

Reimer-Karl J. Trabuer-Veit\& Comp.

Berlin W ro und Leipzig

1934 
Alle Rechte, insbesondere das der Obersetzung in fremde Sprachen, vorbebalten

Archiv-Nr. 220534

Druck von Walter de Grujter \& Con Berlis $\mathbf{W}$ so

Printed in Germany 